\title{
Brachial and central blood pressure and arterial stiffness in adult elite athletes
}

\author{
Fabian Tomschi ${ }^{1,2} \odot \cdot$ Hannah Ottmann ${ }^{1} \cdot$ Wilhelm Bloch $^{2,3} \cdot$ Marijke Grau $^{2} \cdot$ Hans-Georg Predel $^{1}$
}

Received: 22 July 2020 / Accepted: 2 March 2021 / Published online: 13 March 2021

(c) The Author(s) 2021

\begin{abstract}
Purpose Measures of arterial stiffness (AS) and central blood pressure (BP) are indicators for cardiovascular health and possess a high prognostic value in the prediction of cardiovascular events. The effects of physical training are widely unexplored in the context of competitive, high-performance sports. Therefore, we aimed to present possible reference values of brachial and central BP and of AS of adult elite athletes compared to a control group.

Methods A total of 189 subjects participated in this cross-sectional study. Of these were 139 adult elite athletes (70 male, 69 female) performing on top-national and international level, and 50 control subjects ( 26 male, 24 female). Resting brachial and central BP and aortic pulse wave velocity (PWV) were measured and were compared in terms of sex, sport category, and age of the athletes.

Results Results show no difference between athletes and controls in any parameter. Women exhibit lower brachial and central $\mathrm{BP}$ and AS values compared to men. PWV is positively correlated with age. Evaluation of the parameters according to the different sport categories showed that endurance athletes exhibit lower BP and PWV compared to other athletes.

Conclusions This study presents brachial and central BP and PWV values of athletes, suggesting that high-performance sport does not negatively impact AS. The proposed reference values might support a more detailed evaluation of elite athlete's cardiovascular and hemodynamic system and a better assignment to possible risk groups.
\end{abstract}

Keywords Blood pressure $\cdot$ Pulse wave velocity $\cdot$ Arterial stiffness $\cdot$ Reference values $\cdot$ Professional sport

$\begin{array}{ll}\text { Abbreviations } \\ \text { CV } & \text { Cardiovascular } \\ \text { BP } & \text { Blood pressure } \\ \text { SSH } & \text { Spurious systolic hypertension } \\ \text { PP } & \text { Pulse pressure } \\ \text { PWV } & \text { Aortic pulse wave velocity } \\ \text { AS } & \text { Arterial stiffness } \\ \text { SD } & \text { Standard deviation }\end{array}$

Communicated by Massimo pagani.

Fabian Tomschi

fabian.tomschi@gmx.de

1 Institute of Cardiology and Sports Medicine, German Sport University Cologne, Am Sportpark Müngersdorf 6, 50933 Cologne, Germany

2 Molecular and Cellular Sports Medicine, German Sport University Cologne, Am Sportpark Müngersdorf 6, 50933 Cologne, Germany

3 The German Research Center of Elite Sport (Momentum), German Sport University Cologne, Am Sportpark Müngersdorf 6, 50933 Cologne, Germany
CI Confidence interval

bSysBP Brachial systolic blood pressure

bDiaBP Brachial diastolic blood pressure

cSysBP Central systolic blood pressure

cDiaBP Central diastolic blood pressure

\section{Introduction}

It is well known that physical activity results in various health benefits, especially on the cardiovascular (CV) system (Blair 1989). Hence, in elite athletes, the CV risk can be described as very low (Bruno et al. 2011) and it can be assumed that the vascular ageing process is also relatively slow due to several factors. These include, among others, that elite athletes very seldom smoke (Peretti-Watel et al. 2003) and above all are highly active. In the general population, regular physical activity has a well-known blood pressure (BP) lowering effect (Chobanian et al. 2003). However, hypertension is the most common cardiovascular condition in athletes (Caselli et al. 2017; Pelliccia et al. 2017; Matos 
et al. 2011). The underlying reasons are not fully clarified but it was suggested that the mental stress associated with regular competition at top level and the regular high training amount of more than $14 \mathrm{~h}$ per week (Berge et al. 2015) might increase BP. Further, brachial BP might be increased due to the phenomenon of the 'spurious systolic hypertension' (SSH) (Mahmud and Feely 2003) mainly due to extreme pulse pressure (PP) amplification. In this case, central aortic BP can be $30-40 \mathrm{mmHg}$ less that the brachial BP. This phenomenon was mainly observed in young, tall and very active young men (O'Rourke et al. 2000). It was, therefore, recommended to measure central $\mathrm{BP}$ and the aortic pressure wave in subjects who exhibit SSH because a normal central systolic and diastolic BP and a normal aortic pressure waveform most likely indicate that these subjects are not at increased cardiovascular risk (Mahmud and Feely 2003). Besides, athletes might make extensive use of 'ergogenic aids' such as a disproportionately high consumption of caffeine, prescription medications or dietary supplements that might increase BP (Leddy and Izzo 2009).

It was demonstrated that the measurements of central BP and aortic pulse wave velocity (PWV), a direct measure of arterial stiffness (AS), are better related to future cardiovascular events compared to the conventional brachial BP measurement (Karras et al. 2012; McEniery et al. 2014). Both, central BP and PWV were independently correlated with organ damage and cardiovascular manifestations (Kotsis et al. 2011).

However, to the best of our knowledge, there are no scientific publications presenting possible reference values of central BP and PWV of adult elite athletes. Due to the fact that these athletes have a highly active lifestyle, common reference values might be problematic to obtain when referring to adult elite athletes.

Therefore, the aim of the study was to present possible reference data of hemodynamic values, such as brachial and central BP and PWV, of adult elite athletes which can serve as a basis for clinical evaluation. The knowledge gained by this study might be of importance for clinicians dealing with adult elite athletes as the data presented in this study possess an additional clinical and prognostic value for more detailed risk stratification in adult elite athletes.

\section{Methods}

\section{Ethics}

The study and the used protocols were approved by the ethics committee of the German Sport University Cologne. These protocols are in line with the Declaration of Helsinki. Participants gave written informed consent to participate in the study.

\section{Participants}

The inclusion criterion for participation in this study was to have an active status within the elite $\mathrm{A}, \mathrm{B}$, and $\mathrm{C}$ squad system of the German Olympic Federation. This squad system defines the performance level of the athlete. Depending on the discipline, A-level athletes have achieved top-level positions at Olympic Games or World Championships, B-level athletes displayed considerable performance development and are prospective candidates for A-level status, and C-level included the highest national level for prospective young athletes who exhibit the potential to perform at the top international level or who competed successfully in international junior competitions (Zinner et al. 2015). All athletes were selected for participation by their respective sports federation, so they can be considered to be among the national elite.

One hundred and seventy-nine participants (age $23.3 \pm 3.7$, range $18-36$ years) were recruited in total. Of these, 139 were adult elite athletes (70 male, 69 female). Anthropometric data of athletes were as follows: $23.3 \pm 3.8$ years, $177.9 \pm 9.4 \mathrm{~cm}, 72.1 \pm 12.8 \mathrm{~kg}$, $22.6 \pm 2.5 \mathrm{~kg} / \mathrm{m}^{2} .29$ different sports were represented by the participating athletes. Due to varying samples sizes, the athletes were clustered into the following sport groups as done before (Koehler et al. 2012; Zinner et al. 2015; Tomschi et al. 2018): endurance sports $(n=23)$ [triathlon $(n=1)$, long distance running $(n=12)$, middle distance running $(n=9)$, heptathlon $(n=1)$ ]; return and team sports $(n=34)$ [badminton $(n=1)$, baseball $(n=8)$, basketball $(n=1)$, ice hockey $(n=1)$, soccer $(n=9)$, handball $(n=7)$, tennis $(n=1)$, table tennis $(n=4)$,]; combat sports ( $n=28)$ [boxing $(n=2)$, judo $(n=17)$, karate $(n=2)$, wrestler $(n=5)$, taekwondo $(n=2)]$; aesthetic and individual sports $(n=24)$ [fencing $(n=18)$, horse riding $(n=2)$, dancing $(n=2)$, race driver $(n=1)]$; and strength and power sports $(n=30)$ [sprint $(n=8)$, bob-sledge $(n=1)$, highjump $(\mathrm{n}=1)$, canoe $(n=2)$, lifesaver swimming $(n=1)$, rowing $(n=1)$, pole-vault $(n=13)$, and javelin $(n=1)]$.

Furthermore, 50 participants were recruited to serve as a control group (26 male, 24 female) and anthropometric data were as follows: $23.0 \pm 3.0$ years, $175.3 \pm 8.8 \mathrm{~cm}$, $71.6 \pm 11.3 \mathrm{~kg}, 23.2 \pm 2.5 \mathrm{~kg} / \mathrm{m}^{2}$. These control participants were moderately active university students and reported no more than $4 \mathrm{~h}$ of physical activity per week. These control participants did not exert any performance orientated training.

Both groups of participants were told not to consume caffeine or alcohol and refrain from highly vigorous physical activity for at least $12 \mathrm{~h}$ prior to the data collection. The time of the menstrual cycle was not registered in female subjects. Anthropometric data of male and female athletes and of athletes of the different sport types are presented in Table 1. 


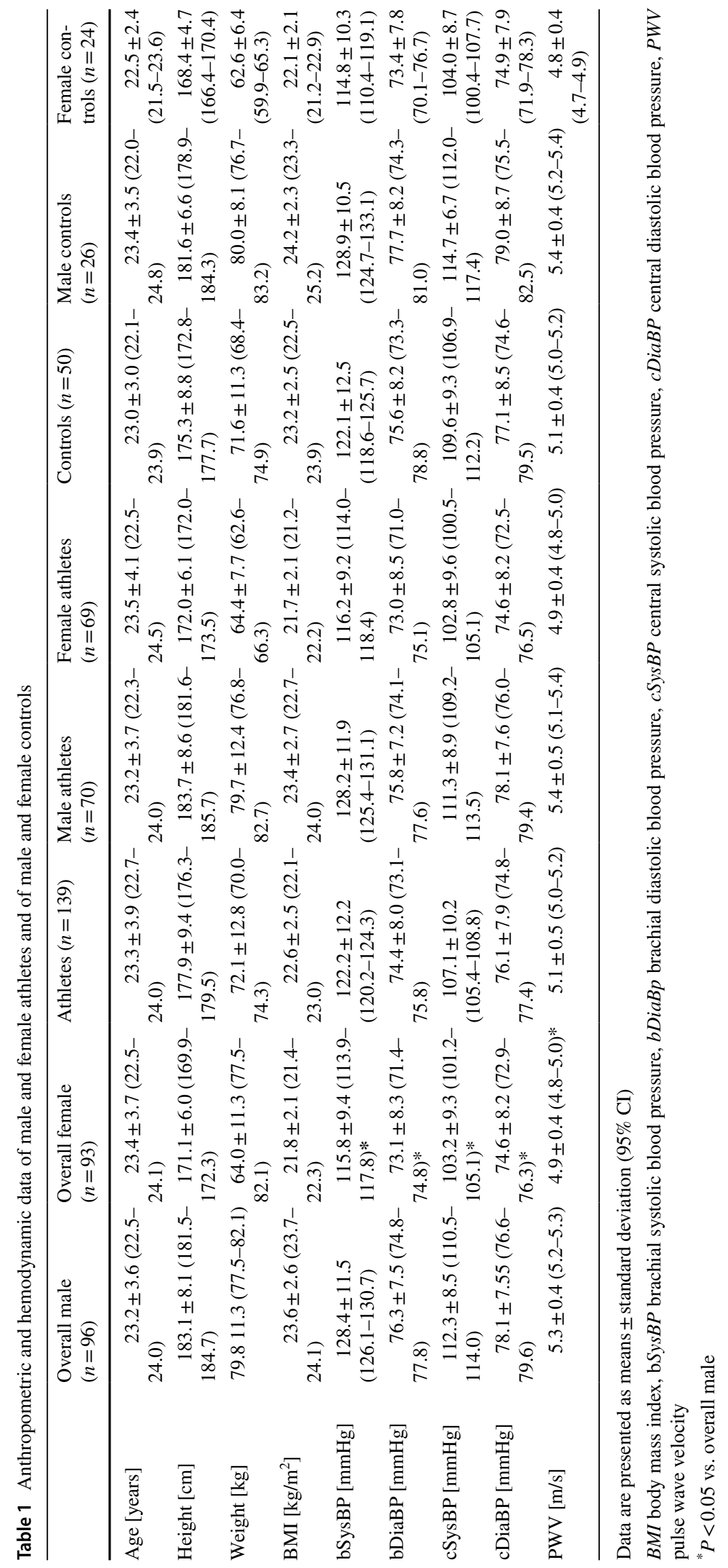


Fig. 1 Representative pulse pressure wave using the MobilO-Graph device (IEM Gmbh, Stolberg, Germany) using an oscillometric cuff. Sehr gut Datenqualität: Ergebnisse glaubhaft $=$ Very good data quality: Results plausible (translated from German)

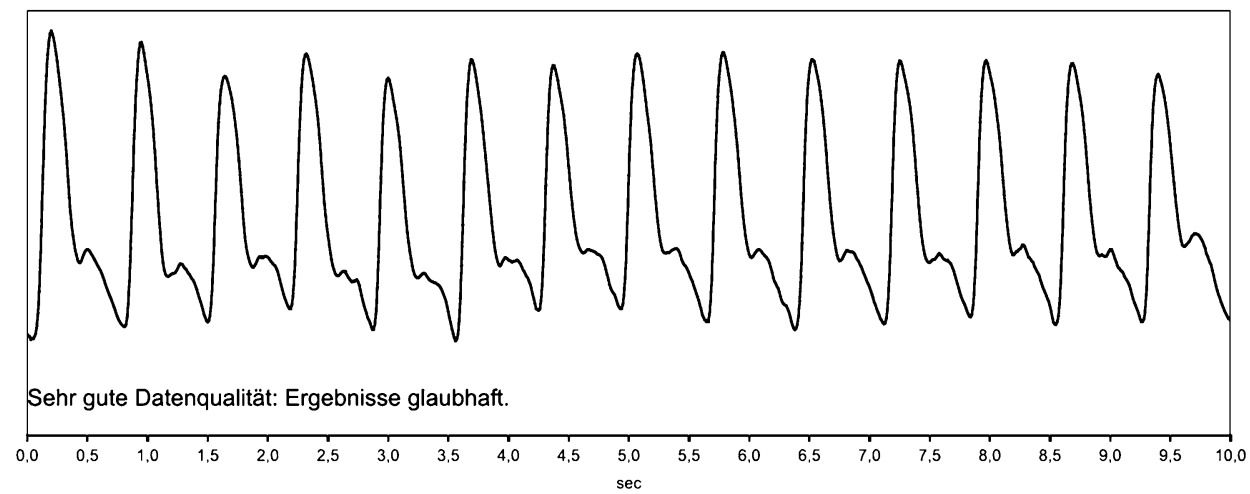

\section{Measurements}

All measurements were performed using a Mobil-O-Graph device (IEM, Stolberg, Germany) as a validated device for the measurement of brachial BP (Franssen and Imholz 2010), central BP (Weiss et al. 2012), and PWV (Hametner et al. 2013) with a novel transfer function-like algorithm, using brachial cuff-based waveform recordings. For central systolic pressure, calculation and other measures of AS an integrated transfer function (ARCSolver algorithm) was used (Weber et al. 2011; Wassertheurer et al. 2010). This algorithm published by Wassertheurer et al. (2010) is based on the algorithm developed by Karamanoglu et al. (1993). Wassertheurer et al. (2010) used a modified cuff by adding a high-fidelity pressure sensor with increased accuracy which allowed them to transform the brachial artery pressures to aortic pressures, using a frequency-based general transfer function similar to a previous one developed by Karamanoglu et al. (1993). Indeed, the mean bias between the ARCSolver method, as it is known, and the technique of Karamanoglu et al. (1993) was $0.1 \mathrm{mmHg}$ (SD $3.1 \mathrm{mmHg}$ ).

First, the device measures the peripheral BP. After $30 \mathrm{~s}$ of pause, the device measures further hemodynamic parameters which are presented in the software output. The time duration of the entire measurement is 3-4 min. The parameters that were evaluated were systolic (bSysBP) and diastolic brachial BP (bDiaBP), systolic (cSysBP) and diastolic central BP (cDiaBP) and PWV. PWV was shown to be the most reliable measure of AS (O'Rourke et al. 2002; Kim et al. 2007). Compared to the invasive measurement of the central systolic pressure and established radial tonometry with inbuilt generalized transfer function, the ARCSolver algorithm showed good agreement (Weber et al. 2011; Wassertheurer et al. 2010).

All hemodynamic measurements were conducted following the guidelines for the management of arterial hypertension (Williams et al. 2018). Participants were in a sitting position (after $10 \mathrm{~min}$ of rest) in a quiet room at the same time of day (between 9 and 11 a.m.). The cuff was placed at the level of the heart with cuffs of correct size and in accordance to the participants' arm circumference. Measurements were repeated, if the quality of the measured arterial pressure wave was poor. By doing so, it was possible obtain an adequate good quality arterial pressure wave from every participating subject. The quality of the arterial pressure wave was checked automatically by the software program and visually by trained medical staff. A representative pressure wave can be found in Fig. 1.

\section{Statistical analyses}

Statistical analyses of the data were performed using statistics software package GraphPad Prism 6 (La Jolla, USA). The data are reported as means \pm standard deviation (SD) and $95 \%$ confidence interval (CI).

To compare hemodynamic values (bSysBP, bDiaBP, cSysBP, cDiaBP, and PWV) between athletes and controls, a two-way ANOVA with the factors 'gender' (male or female) and 'group' (control or athlete) was applied. Besides, a two-way ANOVA with the factors 'gender' (male or female) and 'sport category' (endurance, return and team, combat, aesthetic and individual, strength and power) was applied to determine differences in hemodynamic parameters between the five different sport categories and between male and female athletes. If main effects were observed, Tukey post hoc analyses were used to locate differences between sport categories. Bonferroni post hoc tests were performed to reveal significant differences in interactions between 'gender' and 'sport category' or 'gender' and 'group', respectively.

To evaluate the effect of age on hemodynamic parameters, Pearson's correlation analyses and regression analyses were conducted. 


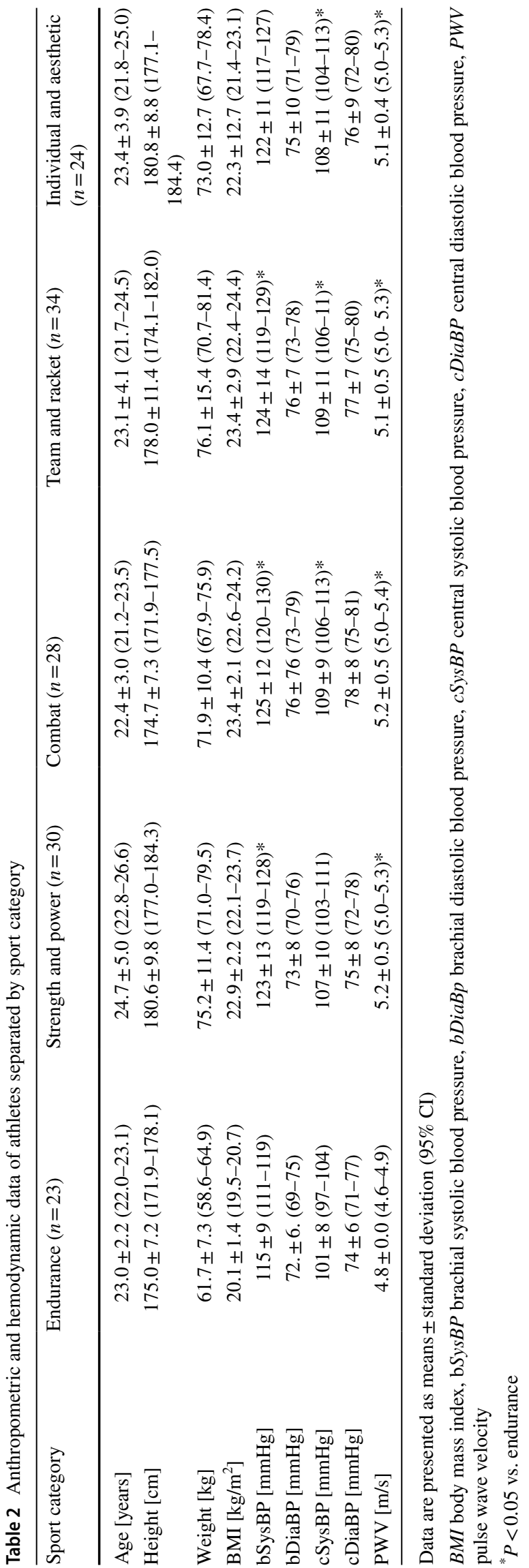

\section{Results}

Means, SD and 95\% CI of the measured hemodynamic parameters of all subjects (athletes and controls) are presented in Table 1. Overall, no main effect for the factor group (athlete or control) was observed between athletes compared to controls in bSysBP, bDiaBP, cSysBP, cDiaBP, and PWV, respectively. A main effect was observed for the factor gender. Female subjects showed significantly lower values in bSysBP $(P<0.001)$, bDiaBP $(P=0.008)$, cSysBP $(P<0.001)$, cDiaBP $(P=0.005)$ and PWV $(P<0.001)$ compared to male subjects. No group $\mathrm{x}$ gender interaction was observed for any parameter.

Means, SD and 95\% CI of the measured hemodynamic parameters of all athletes separated by sport category are presented in Table 2. Statistical analyses of differences between sport categories revealed that bSysBP was significantly different between sport categories $(P=0.005)$. Post hoc analysis revealed that endurance athletes showed lower bSysBP values compared to strength and power $(P=0.040)$, combat $(P=0.009)$ and team and racket athletes $(P=0.017)$. bDiaBP was not different between the different sport categories.

cSysBP was significantly different between the sport categories $(P<0.001)$. Post hoc analysis revealed that cSysBP was significantly lower in endurance athletes compared to combat $(P=0.004)$, team and racket $(P=0.002)$ and individual and aesthetic athletes $(P=0.018)$. cDiaBP was not different between the sport categories.

Statistical analyses revealed that PWV was significantly different between the sport categories $(P=0.002)$. Post hoc analysis revealed that PWV was significantly lower in endurance athletes compared to the categories strength and power $(P=0.005)$, combat $(P=0.006)$, team and racket $(P=0.009)$ and individual and aesthetic $(P=0.015)$.

In athletes, no correlation was observed between age and bSysBP (Fig. 2a). Besides, no correlation was found in athletes between age and cSysBP (Fid. 2d). This was also observed in male athletes, exclusively (Fig. $2 b+e$ ) and in female athletes, exclusively (Fig. $2 c+f$ ). In all athletes, age did not correlate with bDiaBP and cDiaBP (Fig. $3 \mathrm{a}+\mathrm{d}$ ), respectively. In male athletes, age positively correlated with bDiaBP $(P=0.013$; Fig. $3 b)$ and cDiaBP $(P=0.020$; Fig. 3e), respectively. These correlations were not observed in female athletes (Fig. $3 \mathrm{c}+\mathrm{f}$ ). Correlation analyses revealed that PWV was significantly correlated $(P<0.001)$ to the age of the athletes (Fig. 4a). This was observed for male $(P=0.009$; Fig. $4 \mathrm{~b})$ and female athletes $(P<0.001$; Fig. $4 \mathrm{c})$, respectively. 

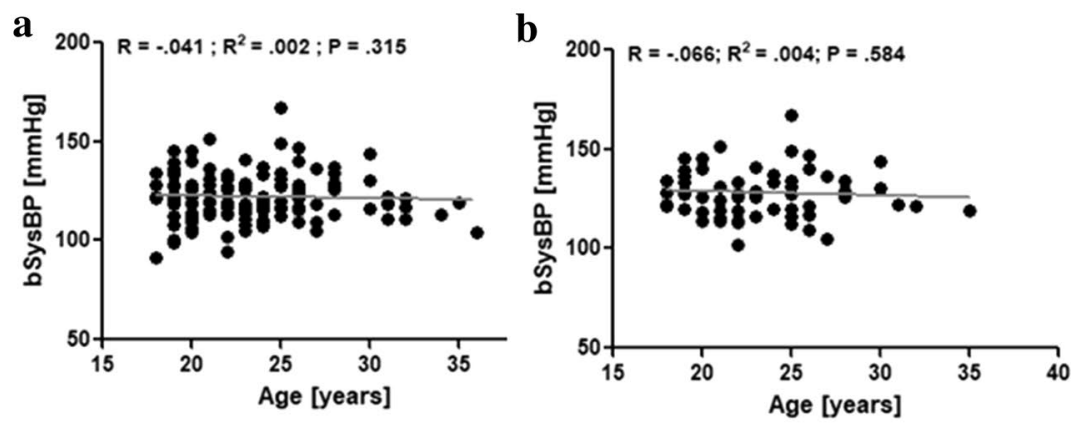

Male athletes
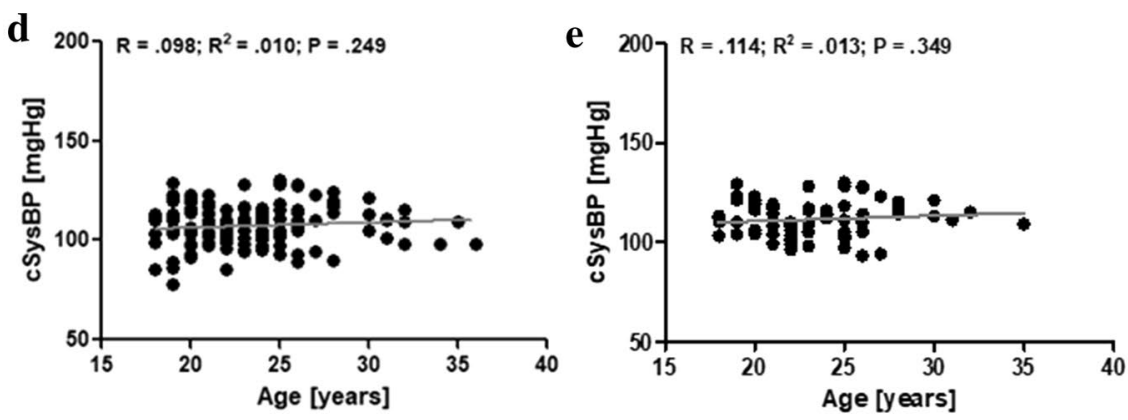

Fig. 2 Correlation analyses of brachial systolic blood pressure (bSysBP) and age of all athletes (a), male athletes (b), and female athletes (c). Correlation analyses of central systolic blood pressure (cSysBP) and age of all athletes (d), male athletes (e), and female athletes (f)

\section{Discussion}

To the best of our knowledge, this study first time presents values of central BP and PWV of adult elite athletes
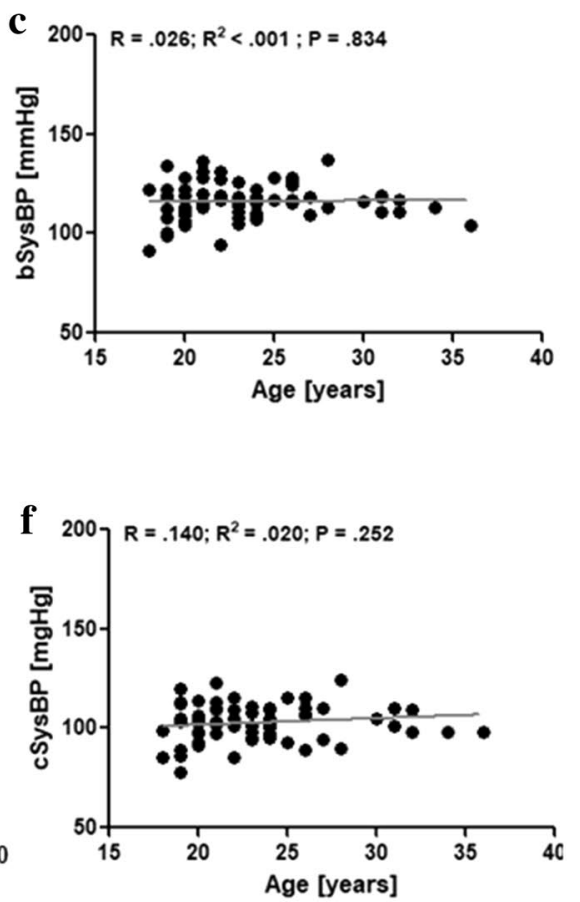
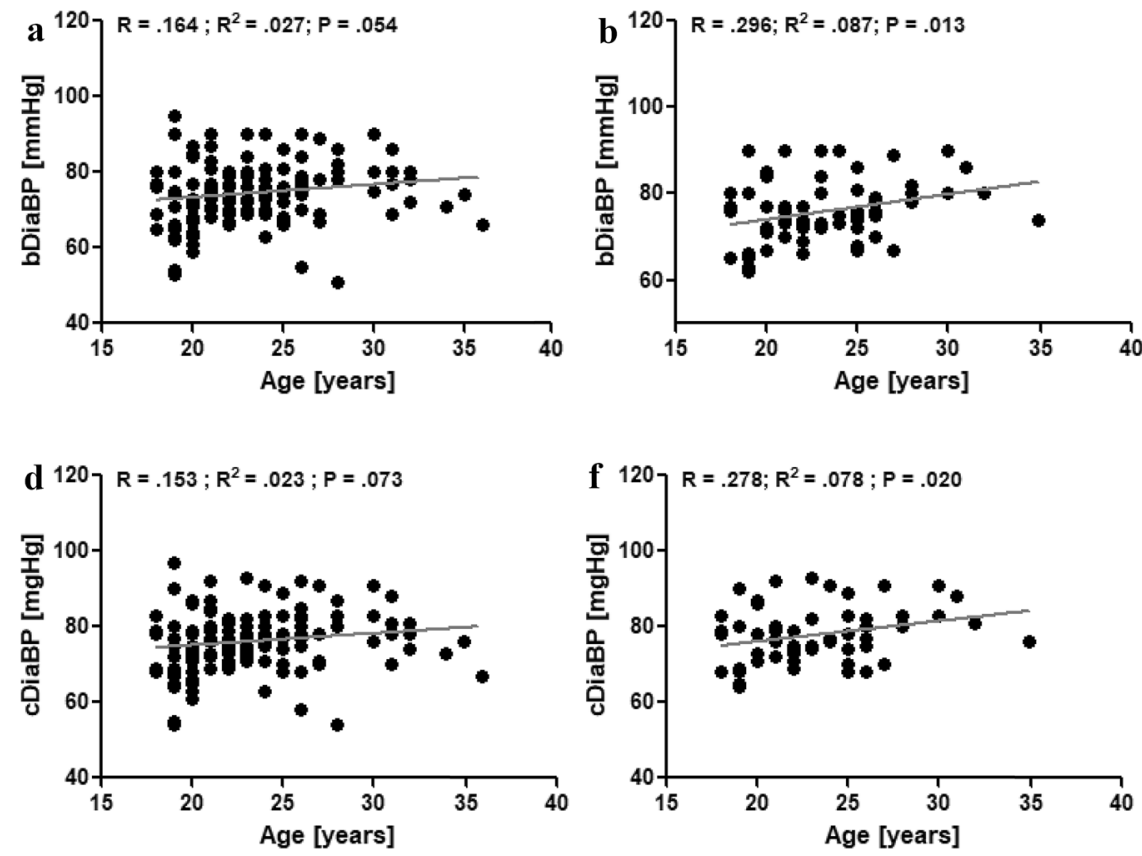

performing different sports and comparing those to values of an age-matched healthy control group. The participating athletes of this study exhibit brachial BP values that are in a healthy range. Male athletes are on average in the

Fig. 3 Correlation analyses of brachial diastolic blood pressure (bDiaBP) and age of all athletes (a), male athletes (b), and female athletes (c). Correlation analyses of central diastolic blood pressure (cDiaBP) and age of all athletes $(\mathbf{d})$, male athletes (e), and female athletes (f) 

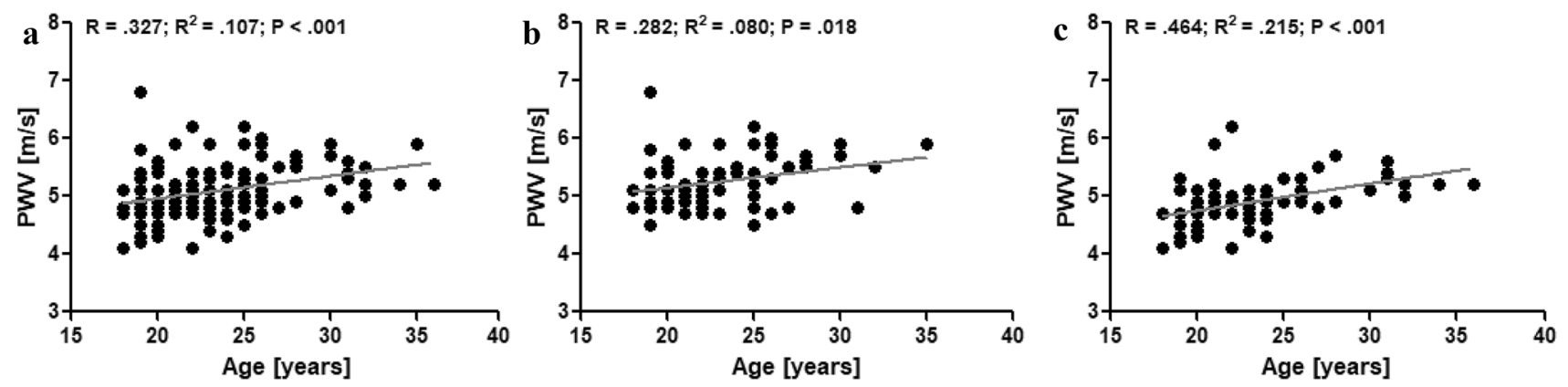

Fig. 4 Correlation analyses of aortic pulse wave velocity (PWV) and age of all athletes (a), male athletes (b), and female athletes (c)

normal systolic BP range and female athletes are in the optimal systolic BP range with respect to the ESH/ESC guidelines (Williams et al. 2018). Further, PWV values of the participating athletes are also lower when comparing them to possible reference data provided by the European Society of Cardiology (ESC) (The Reference Values for Arterial Stiffness' Collaboration 2010). These reference values show that healthy subjects under the age of 30 have a mean PWV of $6.2 \mathrm{~m} / \mathrm{s}$. However, it is important to consider that the methods used are different which might be problematic to compare the results of the present study to the given reference values of the ESC. Due to the fact that the device used in the present study shows great reproducibility (Wassertheurer et al. 2010; Weber et al. 2011), this comparison most likely indicates that the elite athletes exhibit more favourable PWV values compared to the non-athletic population. Further, comparing brachial and central BP values and AS values of elite athletes of the present study to the brachial and central BP and PWV values of the recruited control group, results show that athletes do not exhibit significantly different values in any of the measured parameters. Interestingly, PWV values of the control group are also lower than the above mentioned ESC reference values (The Reference Values for Arterial Stiffness' Collaboration 2010). This is probably due to the mean young age of the control group $(23.0 \pm 3.0$ years $)$. The age of all the participating subjects is of crucial importance in the comparison of PWV values given in the literature as ageing is the main contributor to vascular ageing (Lakatta and Levy 2003). This positive correlation between age and PWV is also observed for athletes in the present study and does not depend on the gender of the athletes. However, the age range of the athletes is rather narrow as athletes can usually only perform top-elite level in a specific age range. This fact limits the informative value (low $R^{2}$ values; see Fig. $4 \mathrm{a}-\mathrm{c}$ ) of the correlation analyses provided. Further studies should be encouraged to explore the vascular health of older (former) athletes.

Interestingly, neither bSysBP nor cSysBP are positively correlated to the age of the athletes of the present study. This is also observed for male and female athletes, exclusively. It is generally assumed that PWV and BP show a great positive correlation even in young age as the flexibility of the arteries is manifested in BP values (Cheung 2010). Extensive physical activity, as performed by elite athletes is known to affect BP (Caselli et al. 2017). However, an early impaired vascular function associated with increased AS usually precedes elevations in resting brachial BP (Kim et al. 2015). This might be one reason for the lack of correlation between age and bSysBP or cSysBP, respectively.

Diastolic BP was shown to be of clinical importance as it indicates a potential risk for future cardiovascular complications (Franklin 2007) and the present study shows that bDi$\mathrm{aBP}$ and cDiaBP are positively correlated with age in male athletes. Interestingly, this is not observed in female athletes. It is known that diastolic BP rises with age predominantly in the male population in age groups under 45 years (Martins et al. 2001). This might explain this correlation found in male athletes.

The present data show in general that female subjects exhibit a lower bSysBP, cSysBP and a lower PWV. These results are in line with the current literature showing that young women who do not perform professional sports show lower brachial BP as well as lower PWV values (The Reference Values for Arterial Stiffness' Collaboration 2010). In addition, in athletes, it was shown that female athletes exhibit lower brachial BP values compared to male athletes (Caselli et al. 2017). The exact reasons for the lower BP and PWV values observed in pre-menopausal women are not entirely understood but it is suggested that the hormone oestrogen plays a pivotal role in cardiovascular and hemodynamic sex differences. Estrogens influence the vaso-reactivity that has a relaxing effect on peripheral resistance vessels (Li and Kloner 1995; Penna et al. 2009).

Looking at the hemodynamic values of athletes of the different sport categories, it is observed that endurance athletes have lowest bSysBP values. These values are lower than those of the athletes of the categories combat, and team and racket sports. In addition, cSysBP is lowest in endurance athletes and significantly lower compared to cSysBP values 
of athletes of the categories combat, team and racket, and individual and aesthetic sports. These results are in line with the current knowledge which is that in recreational sport settings endurance dominated exercise programs are particularly effective in lowering peripheral and central systolic BP (Tanaka et al. 2000). This phenomenon was also previously observed in elite athletes. It was shown in a meta-analysis that endurance-trained athletes exhibit lower brachial BP compared to strength-trained athletes (Berge et al. 2015).

In the present study, endurance athletes show significantly lower PWV values compared to all other athletes of other categories. It was demonstrated that rather endurance exercise interventions improve PWV compared to resistance exercise interventions (Ashor et al. 2014). Several studies further suggest that especially strength training interventions can lead to increases in BP and AS (Otsuki et al. 2007; Bertovic et al. 1999; Choi et al. 2010; Collier et al. 2011; Cortez-Cooper et al. 2005). However, studies also report that resistance training interventions do not lead to increases of AS (Casey et al. 2007; Cortez-Cooper et al. 2008; Rakobowchuk et al. 2005). In a meta-analysis, it was reported that high-intensity resistance training leads to increases in AS of 11.6\%. In contrast, moderateintensity resistance training did not show such association (Miyachi 2013). It was further suggested that combined training, i.e. resistance and aerobic endurance training, did not induce stiffening of the arteries ( $\mathrm{Li}$ et al. 2015). Besides, Montero et al. showed that combined training interventions do not lead to increases in AS but that aerobic endurance interventions are more effective in reducing AS (Montero et al. 2015). In the present study, all sport categories, except for endurance athletes, can be described as hybrid sport categories in which a well-established endurance and strength capacity is a prerequisite for success in the respective sport category (Nader 2006). Differential effects stemming from different training stimuli on the vascular system are, therefore, unlikely and support the suggestion that combined training does not lead to increased AS (Li et al. 2015).

The major strength of the present study is that a high number of adult elite athletes was recruited who perform on top national and international level. However, we also need to acknowledge some limitations. The cross-sectional study design needs to be mentioned as a limitation because it cannot directly measure cause and effect. Yet, all participating athletes were part of the national elite squat system suggesting that a chronic sport type specific training can be assured for every athlete over a long duration of time. Neither specific data of the training history of the elite athletes were obtained, nor were exact training schedules of the athletes recorded. Besides, the effect of the menstrual cycle in female athletes was not considered in this study. Though, studies show that the phase of the menstrual cycle has little effects on hemodynamic values (Augustine et al. 2018; Papaioannou et al. 2009). Further, all athletes and control subjects were in a young adult age. It would be interesting to study the effects of performance orientated training in older adults to evaluate whether intensive training intensifies the age-related physiological processes that contribute to mechanisms, such as earlier vascular ageing. Lastly, it needs to be mentioned that all measurements in the present study were conducted with one and the same device and the presented values are stated as means with SD and 95\% CI. Yet, values obtained in the individual athlete or patient might not fit into the presented results for a number of reasons (e.g. different diagnostic device used, different time of the day, different pre-measurement activity, prior use of 'ergogenic aids' such as large amounts of caffeine, or a potential lack of accuracy for estimates of central aortic blood pressures and PWV).

\section{Conclusion}

This study for the first time presents possible reference values for brachial and central BP and PWV, a measure of AS. The results indicate that athletes in general do not exhibit different hemodynamic values compared to an age-matched, healthy control group. Within athletes, those who perform endurance dominant sports show lower BP and AS values. The present data suggest that high-performance sport in young athletes does not negatively impact AS.

Furthermore, the proposed reference values not only enable a general evaluation of elite athlete's cardiovascular and hemodynamic system, but also a better assignment to risk groups. Due to their high prognostic value AS and central BP should be additionally considered to the athlete's brachial BP.

Acknowledgements The authors would like to thank Anke Schmitz for her excellent technical support.

Parts of the results were presented at the 41. Congress of the German Hypertension Society (Deutsche Hochdruckliga e.V. DHL ${ }^{\circledR}$ Deutsche Gesellschaft für Hypertonie und Prävention) at November 11th 2017 in Mannheim, Germany.

Author contributions The contributions of the authors were as follows: FT and HGP had the original idea for the study. FT, HO, HGP, and MG contributed to conception or design of the study and analysis or interpretation of the data of the present study. FT and HO drafted the manuscript, and HGP, WB and MG critically revised the manuscript for important intellectual content.

Funding Open Access funding enabled and organized by Projekt DEAL. No external financial support was received. 


\section{Declarations}

Conflict of interest The authors declared no potential conflicts of interest with respect to the research, authorship, and/or publication of this article.

Open Access This article is licensed under a Creative Commons Attribution 4.0 International License, which permits use, sharing, adaptation, distribution and reproduction in any medium or format, as long as you give appropriate credit to the original author(s) and the source, provide a link to the Creative Commons licence, and indicate if changes were made. The images or other third party material in this article are included in the article's Creative Commons licence, unless indicated otherwise in a credit line to the material. If material is not included in the article's Creative Commons licence and your intended use is not permitted by statutory regulation or exceeds the permitted use, you will need to obtain permission directly from the copyright holder. To view a copy of this licence, visit http://creativecommons.org/licenses/by/4.0/.

\section{References}

Ashor AW, Lara J, Siervo M, Celis-Morales C, Mathers JC (2014) Effects of exercise modalities on arterial stiffness and wave reflection: a systematic review and meta-analysis of randomized controlled trials. PLoS ONE 9(10):e110034. https://doi.org/10.1371/ journal.pone.0110034

Augustine JA, Nunemacher KN, Heffernan KS (2018) Menstrual phase and the vascular response to acute resistance exercise. Eur J Appl Physiol 118(5):937-946. https://doi.org/10.1007/ s00421-018-3815-1

Berge HM, Isern CB, Berge E (2015) Blood pressure and hypertension in athletes: a systematic review. Br J Sports Med 49(11):716-723. https://doi.org/10.1136/bjsports-2014-093976

Bertovic DA, Waddell TK, Gatzka CD, Cameron JD, Dart AM, Kingwell BA (1999) Muscular strength training is associated with low arterial compliance and high pulse pressure. Hypertension 33(6):1385-1391. https://doi.org/10.1161/01.HYP.33.6.1385

Blair SN (1989) Physical fitness and all-cause mortality. JAMA 262(17):2395. https://doi.org/10.1001/jama.1989.0343017005 7028

Bruno RM, Cartoni G, Taddei S (2011) Hypertension in special populations: athletes. Future Cardiol 7(4):571-584. https://doi.org/10. $2217 /$ fca. 11.33

Caselli S, Vaquer Sequì A, Lemme E, Quattrini F, Milan A, D'Ascenzi F, Spataro A, Pelliccia A (2017) Prevalence and management of systemic hypertension in athletes. Am J Cardiol 119(10):16161622. https://doi.org/10.1016/j.amjcard.2017.02.011

Casey DP, Beck DT, Braith RW (2007) Progressive resistance training without volume increases does not alter arterial stiffness and aortic wave reflection. Exp Biol Med (Maywood, NJ) 232(9):12281235. https://doi.org/10.3181/0703-RM-65

Cheung Y-F (2010) Arterial stiffness in the young: assessment, determinants, and implications. Korean Circ J 40(4):153-162. https:// doi.org/10.4070/kcj.2010.40.4.153

Chobanian AV, Bakris GL, Black HR, Cushman WC, Green LA, Izzo JL, Jones DW, Materson BJ, Oparil S, Wright JT, Roccella EJ (2003) Seventh report of the Joint National Committee on prevention, detection, evaluation, and treatment of high blood pressure. Hypertension (Dallas, TX) 42(6):1206-1252. https://doi.org/10. 1161/01.HYP.0000107251.49515.c2

Choi Y, Maeda S, Otsuki T, Miyaki A, Shimojo N, Yoshizawa M, Shiraki H, Ajisaka R (2010) Oxidative stress and arterial stiffness in strength- and endurance-trained athletes. Artery Res 4(2):52-58. https://doi.org/10.1016/j.artres.2010.04.002

Collier SR, Frechette V, Sandberg K, Schafer P, Ji H, Smulyan H, Fernhall B (2011) Sex differences in resting hemodynamics and arterial stiffness following 4 weeks of resistance versus aerobic exercise training in individuals with pre-hypertension to stage 1 hypertension. Biol Sex Differ 2(1):9. https://doi.org/10.1186/ 2042-6410-2-9

Cortez-Cooper MY, DeVan AE, Anton MM, Farrar RP, Beckwith KA, Todd JS, Tanaka H (2005) Effects of high intensity resistance training on arterial stiffness and wave reflection in women. Am J Hypertens 18(7):930-934. https://doi.org/10.1016/j.amjhyper. 2005.01.008

Cortez-Cooper MY, Anton MM, DeVan AE, Neidre DB, Cook JN, Tanaka H (2008) The effects of strength training on central arterial compliance in middle-aged and older adults. Eur J Cardiovasc Prev Rehabil 15(2):149-155. https://doi.org/10.1097/HJR.0b013 e3282f02fe2

de Matos LDNJ, Caldeira NDAO, Perlingeiro PDS, dos Santos ILG, Negrao CE, Azevedo LF (2011) Cardiovascular risk and clinical factors in athletes: 10 years of evaluation. Med Sci Sports Exerc 43(6):943-950. https://doi.org/10.1249/MSS.0b013e318203d5cb

Franklin SS (2007) The importance of diastolic blood pressure in predicting cardiovascular risk. J Am Soc Hypertens JASH 1(1):8293. https://doi.org/10.1016/j.jash.2006.11.004

Franssen PML, Imholz BPM (2010) Evaluation of the Mobil-O-Graph new generation ABPM device using the ESH criteria. Blood Press Monit 15(4):229-231

Hametner B, Wassertheurer S, Kropf J, Mayer C, Eber B, Weber T (2013) Oscillometric estimation of aortic pulse wave velocity: comparison with intra-aortic catheter measurements. Blood Press Monit 18(3):173-176. https://doi.org/10.1097/MBP.0b013e3283 614168

Karamanoglu M, O’Rourke MF, Avolio AP, Kelly RP (1993) An analysis of the relationship between central aortic and peripheral upper limp pressure waves in man. Eur Heart J 14(2):160-167. https:// doi.org/10.1093/eurheartj/14.2.160

Karras A, Haymann J-P, Bozec E, Metzger M, Jacquot C, Maruani G, Houillier P, Froissart M, Stengel B, Guardiola P, Laurent S, Boutouyrie P, Briet M (2012) Large artery stiffening and remodeling are independently associated with all-cause mortality and cardiovascular events in chronic kidney disease. Hypertension (Dallas, TX) 60(6):1451-1457. https://doi.org/10.1161/hyper tensionaha.112.197210

Kim EJ, Park CG, Park JS, Suh SY, Choi CU, Kim JW, Kim SH, Lim HE, Rha SW, Seo HS, Oh DJ (2007) Relationship between blood pressure parameters and pulse wave velocity in normotensive and hypertensive subjects: invasive study. J Hum Hypertens 21(2):141-148. https://doi.org/10.1038/sj.jhh.1002120

Kim JH, Sher S, Wang F, Berkstresser B, Shoop JL, Galante A, Al Mheid I, Ghasemzadeh N, Hutter AM, Williams BR, Sperling LS, Weiner RB, Quyyumi AA, Baggish AL (2015) Impact of American-style football participation on vascular function. Am J Cardiol 115(2):262-267. https://doi.org/10.1016/j.amjcard. 2014.10.033

Koehler K, Braun H, Achtzehn S, Hildebrand U, Predel H-G, Mester J, Schänzer W (2012) Iron status in elite young athletes: genderdependent influences of diet and exercise. Eur J Appl Physiol 112(2):513-523. https://doi.org/10.1007/s00421-011-2002-4

Kotsis V, Stabouli S, Karafillis I, Nilsson P (2011) Early vascular aging and the role of central blood pressure. J Hypertens 29(10):1847-1853. https://doi.org/10.1097/HJH.0b013e3283 $4 \mathrm{a} 4 \mathrm{~d} 9 \mathrm{f}$

Lakatta EG, Levy D (2003) Arterial and cardiac aging: major shareholders in cardiovascular disease enterprises: part I: aging arteries: a "set up" for vascular disease. Circulation 107(1):139-146 
Leddy JJ, Izzo J (2009) Hypertension in athletes. J Clin Hypertens (Greenwich, CT) 11(4):226-233. https://doi.org/10.1111/j. 1751-7176.2009.00100.x

Li K (1995) Is there a gender difference in infarct size and arrhythmias following experimental coronary occlusion and reperfusion? J Thromb Thromb 2(3):221-225

Li Y, Hanssen H, Cordes M, Rossmeissl A, Endes S, SchmidtTrucksäss A (2015) Aerobic, resistance and combined exercise training on arterial stiffness in normotensive and hypertensive adults: a review. Eur J Sport Sci 15(5):443-457. https://doi.org/ 10.1080/17461391.2014.955129

Mahmud A, Feely J (2003) Spurious systolic hypertension of youth: fit young men with elastic arteries. Am J Hypertens 16(3):229-232

Martins D, Nelson K, Pan D, Tareen N, Norris K (2001) The effect of gender on age-related blood pressure changes and the prevalence of isolated systolic hypertension among older adults: data from NHANES III. J Gend Specif Med 4(3):10-13

McEniery CM, Cockcroft JR, Roman MJ, Franklin SS, Wilkinson IB (2014) Central blood pressure: current evidence and clinical importance. Eur Heart J 35(26):1719-1725. https://doi.org/10. 1093/eurheartj/eht565

Miyachi M (2013) Effects of resistance training on arterial stiffness: a meta-analysis. Br J Sports Med 47(6):393-396. https://doi. org/10.1136/bjsports-2012-090488

Montero D, Vinet A, Roberts CK (2015) Effect of combined aerobic and resistance training versus aerobic training on arterial stiffness. Int J Cardiol 178:69-76. https://doi.org/10.1016/j.ijcard. 2014.10.147

Nader GA (2006) Concurrent strength and endurance training: from molecules to man. Med Sci Sports Exerc 38(11):1965-1970. https://doi.org/10.1249/01.mss.0000233795.39282.33

O'Rourke MF, Vlachopoulos C, Graham RM (2000) Spurious systolic hypertension in youth. Vasc Med (London, England) 5(3):141-145. https://doi.org/10.1177/1358836X0000500303

O'Rourke MF, Staessen JA, Vlachopoulos C, Duprez D, Plante GE (2002) Clinical applications of arterial stiffness; definitions and reference values. Am J Hypertens 15(5):426-444

Otsuki T, Maeda S, Iemitsu M, Saito Y, Tanimura Y, Ajisaka R, Miyauchi T (2007) Vascular endothelium-derived factors and arterial stiffness in strength- and endurance-trained men. Am J Physiol Heart Circ Physiol 292(2):91. https://doi.org/10.1152/ ajpheart.00678.2006

Papaioannou TG, Stamatelopoulos KS, Georgiopoulos G, Vlachopoulos C, Georgiou S, Lykka M, Lambrinoudaki I, Papamichael CM, Stefanadis CI (2009) Arterial wave reflections during the menstrual cycle of healthy women: a reproducibility study. Hypertension (Dallas, TX) 54(5):1021-1027. https://doi.org/ 10.1161/Hypertensionaha.109.137703

Pelliccia A, Adami PE, Quattrini F, Squeo MR, Caselli S, Verdile L, Maestrini V, Di Paolo F, Pisicchio C, Ciardo R, Spataro A (2017) Are Olympic athletes free from cardiovascular diseases? Systematic investigation in 2352 participants from Athens 2004 to Sochi 2014. Br J Sports Med 51(4):238-243. https://doi.org/ 10.1136/bjsports-2016-096961

Penna C, Tullio F, Merlino A, Moro F, Raimondo S, Rastaldo R, Perrelli M-G, Mancardi D, Pagliaro P (2009) Postconditioning cardioprotection against infarct size and post-ischemic systolic dysfunction is influenced by gender. Basic Res Cardiol 104(4):390-402. https://doi.org/10.1007/s00395-008-0762-8

Peretti-Watel P, Guagliardo V, Verger P, Pruvost J, Mignon P, Obadia Y (2003) Sporting activity and drug use. Alcohol, cigarette and cannabis use among elite student athletes. Addiction 98(9):1249-1256. https://doi.org/10.1046/j.1360-0443.2003. 00490. $\mathrm{x}$

Rakobowchuk M, McGowan CL, de Groot PC, Bruinsma D, Hartman JW, Phillips SM, MacDonald MJ (2005) Effect of whole body resistance training on arterial compliance in young men. Exp Physiol 90(4):645-651. https://doi.org/10.1113/expphysiol. 2004.029504

Tanaka H, Dinenno FA, Monahan KD, Clevenger CM, DeSouza CA, Seals DR (2000) Aging, habitual exercise, and dynamic arterial compliance. Circulation 102(11):1270-1275

The Reference Values for Arterial Stiffness' Collaboration (2010) Determinants of pulse wave velocity in healthy people and in the presence of cardiovascular risk factors: "establishing normal and reference values." Eur Heart J 31(19):2338-2350. https:// doi.org/10.1093/eurheartj/ehq165

Tomschi F, Bloch W, Grau M (2018) Impact of type of sport, gender and age on red blood cell deformability of elite athletes. Int J Sports Med 39(1):12-20. https://doi.org/10. 1055/s-0043-119879

Wassertheurer S, Kropf J, Weber T, van der Giet M, Baulmann J, Ammer M, Hametner B, Mayer CC, Eber B, Magometschnigg D (2010) A new oscillometric method for pulse wave analysis: comparison with a common tonometric method. J Hum Hypertens 24(8):498-504. https://doi.org/10.1038/jhh.2010.27

Weber T, Wassertheurer S, Rammer M, Maurer E, Hametner B, Mayer CC, Kropf J, Eber B (2011) Validation of a brachial cuff-based method for estimating central systolic blood pressure. Hypertension (Dallas, TX) 58(5):825-832. https://doi.org/ 10.1161/Hypertensionaha.111.176313

Weiss W, Gohlisch C, Harsch-Gladisch C, Tölle M, Zidek W, van der Giet M (2012) Oscillometric estimation of central blood pressure: validation of the Mobil-O-Graph in comparison with the SphygmoCor device. Blood Press Monit 17(3):128-131. https:// doi.org/10.1097/MBP.0b013e328353ff63

Williams B, Mancia G, Spiering W, Agabiti Rosei E, Azizi M, Burnier M, Clement DL, Coca A, de Simone G, Dominiczak A, Kahan T, Mahfoud F, Redon J, Ruilope L, Zanchetti A, Kerins M, Kjeldsen SE, Kreutz R, Laurent S, Lip GYH, McManus R, Narkiewicz K, Ruschitzka F, Schmieder RE, Shlyakhto E, Tsioufis C, Aboyans V, Desormais I (2018) 2018 ESC/ESH Guidelines for the management of arterial hypertension. Eur Heart J 39(33):3021-3104. https://doi.org/10.1093/eurheartj/ ehy339

Zinner C, Sperlich B, Wahl P, Mester J (2015) Classification of selected cardiopulmonary variables of elite athletes of different age, gender, and disciplines during incremental exercise testing. SpringerPlus 4:544. https://doi.org/10.1186/s40064-015-1341-8

Publisher's Note Springer Nature remains neutral with regard to jurisdictional claims in published maps and institutional affiliations. 